\title{
Management of Chronic Empyema Cavity in Cachectic Patients: Review of 30 cases
}

\author{
Ahmed Abdul-Ameer Daffar* \\ Ali Mohsin Obeid Al- Sinjery** \\ Aqeel Salman Saleh Al-Mindel** \\ Rafid Remthan Hussein Al-Temimi** \\ * College of Medicine / Thi-Qar University \\ ** Directorate of Health / Thi-Qar \\ *Ahmed-abdalameer@utq.edu.iq
}

\section{Abstract}

Background: An empyema, or empyema thoracis, is a collection of purulent material in the pleural space. The management and presentation varies considerably by managing physician, geographic location, and economic resources.

Objectives: The aim of this study was to re-emphasize the importance of open drainage in the treatment of advanced thoracic empyema and to assess it's effectiveness in patients who did not respond to more conservative treatment like tube thoracostomy and/ or are not fit for major surgical interventions like thoracotomy.

Patients and Methods: The current retrospective study was carried out in the Cadiothoracic and Vascular Unit in Ibn- Al-Nafees Teaching Hospital ( Iraq / Baghdad ) \& AL-Hussein Teaching Hospital ( Iraq / Thi-Qar ) from April 2009 to February 2017. The number of patients included in the study was (30) patients. Most of our patients were too cachectic to tolerate thoracotomy for decortication or more aggressive treatment. We treated them by open drainage with rib resection. Thoracoplasty was added to some of them.

Results: The highest incidence of chronic non-resolving empyema cavity was among patients between (41-60) years old. The commonest type of surgical procedure applied on patients was Elloeser flap whithout thoracoplasty. Certain Co-morbidities could be recognized in patients with chronic empyema cavity like D.M., Hypertension, Ischemic heart disease \& Malignancy. The duration after which the open drainage system closes varies widely between the patients depending on several factors like ( size of chronic empyema cavity, the presence of co-morbidities, adherence to antibiotics, the presence of bronchopleural fistula, etc...). 
Conclusion: The surgical procedure of Modified Elloeser flap was very effective in treatment of chronic empyema cavity in patients who did not respond to more conservative treatment like tube thoracostomy and/ or are not fit for major surgical interventions like thoracotomy. Open drainage should not be ignored as one of the therapeutic options in treatment of advanced thoracic empyema. It might be the best therapeutic modality in cachectic patients where the facilities for more aggressive treatment are not possible.

Key words:, Pleural empyema, Empyema thoracis, Thoracic empyema, Chronic empyema cavity.

\section{Introduction}

An empyema, or empyema thoracis, is a collection of purulent material in the pleural space. The management and presentation varies considerably by managing physician, geographic location, and economic resources. In the United Kingdom, up to $40 \%$ of patients with an empyema come to surgery after failed catheter drainage, and overall $20 \%$ of patients with empyema die. In third world countries, the usual organisms that cause an empyema differ greatly from what is seen in the developed world. Management varies from simple open drainage to complex interventional radiologic drainage with expensive fibrinolytics. The first mention of an empyema is attributed to Hippocrates. He described the natural history of empyema by stating. In pleuritic afflictions when the disease is not purged off in 14 days, it usually results in an empyema. The management was as follows: a warm bath, set him on a stool, which is not wobbly listen to see on which side a noise is heard; and right at this place, preferably on the left, make an incision, then it produces death more rarely. The method of open drainage described by
Hippocrates has remained in use for more than 2,000 years. Trousseau, in 1843,

described the use of thoracentesis and drainage. Several years after Trousseau's introduction of thoracentesis, Hewett described closed pleural drainage. A major advance in treatment outcome occurred as a result of the report of Graham and Bell as part of the U.S. Army Corps Empyema Commission in 1918. Before their report, open drainage was the standard treatment for all empyema that developed during World War I. The mortality rate was a staggering $30 \%$ to $70 \%$. Through careful analysis of the patient population, they deduced that the treatment should follow several principles. There was drainage, but with careful avoidance of an open pneumothorax. They further described the concepts of early sterilization and obliteration of the cavity and the importance of nutrition in these patients. With adoption of these simple principles the mortality fell to $10 \%$ to $15 \%$. In 1945 , Tillet described the use of fibrinolytics, and in 1972, Clagett published a paper describing closure of the pleural cavity by filling it with antibiotic solution. More recently, Pairolero as well as Miller have 
expanded the understanding of the use of muscle flaps to treat difficult empyemas.

When treating a patient with a suspected empyema, there are several decisions to make to determine the best management. Initially, almost any patient with an effusion associated with sepsis or pneumonic illness should have a diagnostic pleural fluid sampling. If fluid cannot be obtained, then the use of computed tomography or ultrasound can help to localize the area to be sampled. Patients with frank pus or cloudy fluid should have a chest tube placed immediately. Even a delay of 12 to 24 hours can allow the fluid to thicken so that a decortication will be required. Similarly, when bacteria are seen on Gram stains of the pleural effusion, a chest tube should be inserted. Occasionally, culture and parapneumonic effusion secondary to Pneumococcus may resolve with antibiotics alone, but the possibility of a mixed infection must be considered. Patients with a $\mathrm{pH}<7.2$ should also have a chest tube placed. Other conditions or reasons to place a chest tube include large effusion, loculated (either by computed tomographic scan or ultrasound) effusion, and a patient not responding clinically to antibiotic therapy. Chest tubes can usually be placed at the bedside using mild sedation and infiltration of local anesthetic. The pleural space will usually be acidic, and thus adequate analgesia will be more difficult. Nevertheless, it should be possible to place a chest tube with minimal discomfort when properly performed. The tube should be placed into the pleural fluid collection and located to promote dependent drainage, but not so that the patient has to lie on the tube.

There have been no clinical trials comparing the efficacy of traditional largebore (32- to 36-F) chest tubes versus the thin (10- to 14-F) tubes placed radiographically. Most papers in the literature report good results with either type tube. Similarly, there is no consensus on the best way to manage the chest tube. Small-bore tubes usually need intermittent irrigation with 10 to $30 \mathrm{~mL}$ of normal saline solution via a three-way stopcock. Irrigation is usually not performed with large-bore tubes, because in practice it is more difficult to maintain negative intrapleural pressure and irrigate the tubes. Repeated irrigation may introduce bacteria into the pleural space, but this has also not been studied. Chest tubes are usually placed to $20 \mathrm{~cm} \mathrm{H}_{2} \mathrm{O}$ suction and kept in place until the drainage has fallen to $<300 \mathrm{~mL} / 24$ hours, but again, there is no scientific data to support either of these standard - practices. If the lung fully expands to fill the pleural space, the empyema will usually not recur after closed chest tube drainage alone.

Instillation of intrapleural fibrinolytic therapy to break up loculations and to improve the drainage of an empyema has been in use since approximately 1949 .

Although initial use was associated with numerous problems, including allergic reactions and leukocytosis, newer agents have rekindled interest in the use of intrapleural fibrinolytic drugs to improve pleural drainage. There are four small randomized trials, the largest of which included 128 adult patients who were randomized to receive either intrapleural urokinase, streptokinase, or controlled flushes. The patients who received the urokinase or streptokinase did have increased fluid drainage, but it is unclear whether the instillation of these medications reduced the morbidity, mortality, or need for surgical intervention. There is a larger randomized trial ongoing in the United Kingdom by the Medical Research Council and the British Thoracic 
Society. It is hoped that this will yield some insight into whether these techniques are valuable because their use is variable and based on anecdotal evidence.

Complications associated with the intrapleural fibrinolytics include allergic reactions and fever; however, it is difficult to determine whether the reactions are secondary to the primary illness or are from the introduction of the fibrinolytics. There is also the theoretical possibility that these agents may cause a systemic response, thus interfering with later fibrinolytic therapy that is given systemically for a myocardial infarction or as therapy for other emboli that may develop in the body. For streptokinase the recommended dosage is 250,000 IU daily or 250,000 IU every 12 hours for 3 days; for urokinase, it is 100,000 IU once daily for 3 days. The concept is to improve the drainage via the chest tube and reduce the need for surgery. These medications are most often used in children or in older adults in whom there would be a high risk of numerous comorbidities with surgical intervention.

Other intrapleural agents include streptodornase-alpha 1 DNAse. The concept behind this type of therapy is that the DNAse would liquefy some of the viscous material in the pleural space and improve the drainage. Again, clinical trials will be necessary to assess whether these are effective.

When chest tube drainage is ineffective, surgical intervention is required. Typically, operation is indicated when there is persistent sepsis or a persistent pleural collection that is multiloculated. Other considerations include whether there is a question of malignancy, whether there is a large amount of foreign material in the chest cavity, and whether the patient is immunosuppressed. Bronchoscopy should be performed in most patients who have an empyema because of the possibility of bronchial obstruction, which could be the etiologic factor leading to the empyema. Although this has never been randomly studied, in one British chest physician's series of 119 patients, $40 \%$ underwent bronchoscopy, usually to exclude a cancer that was causing the empyema. Tumor was found in $<4 \%$ of the total sample. However, even though the number is small, the complication rate from the bronchoscopy was extremely low, and thus it would seem to be indicated in patients with an empyema.

The goal of the surgical procedure is to remove the infected material and the fibrinous material to allow the lung to expand so that the parietal and visceral pleura are in apposition. This is accomplished by a decortication. The first successful description of a decortication was by Fowler in 1893. The procedure had also been described by a French surgeon, DeLormae, but the patient died after the procedure. Decortication is most often done through a thoracotomy incision to allow wide access to the pleural cavity and to allow debridement of all the pleural material, as well as the thick rind that has been deposited on the parietal and visceral pleurae. Recently, decortication has been described using a video-assisted thoracoscopic (VATS) approach; however, with the minimally invasive technique, it is difficult and quite time consuming to remove sufficient quantity of the pleural thickening to affect an adequate reexpansion of the lung. The purpose of removing the thickened peel over the surface of the lung is so that it can reexpand and the pleural surfaces can be reopposed, eliminating the potential space that harbors bacteria. If the decortication proves to be technically impossible, such 
that when the visceral pleura is removed, the lung is torn, or an adequate plane cannot be found, it is possible to perform incisions into the visceral pleura, either in a parallel fashion or in a checkerboard fashion, to allow the lung to re-expand. This was first described by Ransohoff in 1900.

At the time of decortication, the fibrinopurulent material removed should be sent for culture and for pathologic examination to rule out pleural malignancy. At the completion of the procedure, the chest cavity should be irrigated with copious quantities of saline solution. Any large air leaks should be repaired with sutures. Smaller peripheral air leaks will usually seal very quickly after surgery. Large-bore chest tubes should be carefully placed in the posterior, anterior, and inferior pleural space and connected to suction immediately to continue to drain the pleural cavity in the postoperative period. Once the drainage has decreased to an acceptable level, usually $<300 \mathrm{~mL} / \mathrm{chest}$ tube/day, and if there is no air leak, the chest tubes can be removed. Success rates with an open decortication are extremely high. A reason for failure is incomplete decortication, leaving a residual space. Certainly, just removing the purulent material and not removing the rind on top of the lung is a setup for failure and almost certainly will result in another operation.

Chest roentgenogram showing a right lower pleural space collection. (B) Computed tomography of the patient in panel A, demonstrating a empyema of the right chest. (C) Chest roentgenogram of the patient in panels A and B after placement of a pigtail catheter via computed tomography guidance. (D) Computed tomography of the patient showing the pigtail catheter in the nearly completely drained empyema.

In some patients, a thoracotomy under general anesthesia is prohibitively risky, and they therefore are not candidates for a decortication. In this very small subset, it is possible to treat the patient with an oldfashioned method by either prolonged chest tube drainage or a thoracotomy and open drainage. As was shown in the 1918 Army Empyema Commission led by Graham and Bell, the mortality rate from empyema dropped significantly when a rib resection and wide surgical drainage was performed after there was complete fusion between the parietal and visceral pleura. Performing a rib resection or open drainage early in an empyema will lead to lung collapse and will be fatal $>50 \%$ of patients. Long-term chest drainage can be performed by placing a chest tube and initially connecting it to closed suction drainage. This will allow the bulk of the infected material to drain. Once a significant period has gone by usually 1 to 2 weeks, the chest tube can be converted to open drainage and a chest $\mathrm{x}$ ray obtained to make sure that the lung does not collapse. If it does not collapse, the chest tube can be shortened and allowed to drain into a gauze sponge. This chest tube is then withdrawn from the chest cavity $2 \mathrm{~cm}$ to $4 \mathrm{~cm}$ every other week while the residual space closes and heals by secondary intention. Obviously this is not a very cosmetic or socially acceptable method of therapy for most patients; however, it is an option when patients are too ill to undergo general anesthesia or have a small to moderate-sized fixed space. This usually results in excellent apposition of the pleural space, although it is quite inconvenient for the patients because they require frequent trips back to the doctor's office for management of the chest tube. Another option, as derived from Eloesser's 
initial description, is to perform a rib resection and create a flap of skin and subcutaneous tissue that keeps the hole open, a procedure known as an openwindow thoracostomy. Initially described by Leo Eloesser in an article in Surgery Gynecology and Obstetrics in 1935, this flap was to be a one-way valve for patients with tuberculous empyema. The flap was not adequately described in the initial reference, so it is unclear how Eloesser was able to provide exit of air from the chest cavity with no collapse of the lung. The subsequent development of antituberculous drugs and antibiotics made the Eloesser flap an obsolete, and the operation rarely needs to be used. There are times, however, when chronically ill patients require open dependent drainage, and this can be performed once there has been pleural synthesis by resecting one or more ribs from the dependent portion of the pleural cavity to be drained. The skin is sutured to the thickened pleural rind to keep the drainage site open. This cavity can then be irrigated daily by the patient, and dressing sponges can be applied. Often, this is a chronic cavity and will remain open for the rest of the patient's life. Rarely will the cavity heal by secondary intention and close spontaneously. In either event, this is a very disabling procedure and should rarely be used except for the most extreme circumstances.

In summary, empyema should be treated by closed-chest drainage. This is usually successful when therapy is instituted early. When closed drainage is unsuccessful, an open decortication should be done. The goal is to remove all the purulent material and allow the lung to expand so the parietal and visceral pleurae can come together. When patients are too ill to tolerate an operation, a small window can be made after sufficient time has allowed the pleural surfaces to fuse, so the lung will not collapse from this open pneumothorax. ${ }^{(1)}$ ${ }^{a}$ Another option, as derived from Eloesser's initial description, is to perform a rib resection and create a flap of skin and subcutaneous tissue that keeps the hole open, a procedure known as an openwindow thoracostomy. Initially described by Leo Eloesser in an article in Surgery Gynecology and Obstetrics in 1935, this flap was to be a one-way valve for patients with tuberculous empyema. The flap was not adequately described in the initial reference, so it is unclear how Eloesser was able to provide exit of air from the chest cavity with no collapse of the lung. The subsequent development of antituberculous drugs and antibiotics made the Eloesser flap an obsolete, and the operation rarely needs to be used. There are times, however, when chronically ill patients require open dependent drainage, and this can be performed once there has been pleural synthesis by resecting one or more ribs from the dependent portion of the pleural cavity to be drained. The skin is sutured to the thickened pleural rind to keep the drainage site open. This cavity can then be irrigated daily by the patient, and dressing sponges can be applied. Often, this is a chronic cavity and will remain open for the rest of the patient's life. Rarely will the cavity heal by secondary intention and close spontaneously. In either event, this is a very disabling procedure and should rarely be used except for the most extreme circumstances.

In summary, empyema should be treated by closed-chest drainage. This is usually successful when therapy is instituted early. When closed drainage is unsuccessful, an open decortication should be done. The goal is to remove all the purulent material 
and allow the lung to expand so the parietal and visceral pleurae can come together. When patients are too ill to tolerate an operation, a small window can be made

\section{Aim of study:}

The aim of this study was assess the effectiveness of Elloeser flap in treatment of chronic empyema cavity in patients who did not respond to more conservative treatment like tube thoracostomy and/ or are not fit for major surgical interventions like thoracotomy and decortication.

\section{Patients and Methods:}

The current retrospective study was carried out in the Cadiothoracic and Vascular Unit in Ibn- Al-Nafees Teaching Hospital ( Iraq / Baghdad ) \& AL-Hussein Teaching Hospital ( Iraq / Thi-Qar ) from April 2009 to February 2017. The number of patients included in the study was (30) patients. Most of our patients were too cachectic to tolerate thoracotomy for decortication or more aggressive treatment. The majority of patients were cachectic with severe loss of weight, fever and loss of appetite and they were in an obvious catabolic state. Chest $\mathrm{X}$ rays were showing total or semi-total collapse of the lung with fluid level in the hemi thorax involved by the empyema. Most of these patients were already on medical treatment according to their causative disease and all of them were initially treated by one or more chest tubes. We treated the patients by open drainage with rib resection and thoracoplasty was added to some of them. None of the patients was in the excudative or the fibro-purulent stage and the mediastinum was fixed. In addition, the parietal and visceral pleura were fused at the edge of after sufficient time has allowed the pleural suarfaces to fuse, so the lung will not collapse from this open pneumothorax. ${ }^{(1)}$

chronic empyema cavity and the open drainage procedure did not lead to collapse of the lung. After carrying out the surgical procedure, daily dressing was needed for the first week after surgery, and then was remarkably less frequent. Change of dressing 2-3 times a week was enough after one month from surgery and became once

weekly after another month in most of the patients. Medical treatment was continued accordingly. In most of the patients, hospitalization was needed for 1-2 weeks only. Subsequently, patients became free of fever with better appetite, and finally all of them began to gain weight remarkably. Later, chest $X$ ray showed the space in the hemithorax free of any air-fluid level and in few weeks proved remarkable lung expansion \& space in between the lung and the chest wall was decreasing continuously until it disappeared in few months. Eventually, the drainage ceased completely and the opening of the open drainage was closed spontaneously with the patient free of symptoms with no need for further surgical treatment. Patience is needed in managing empyema patients with open drainage. The concentration should be paid in the first few days to the clinical evidence of improvement in the general condition of the patients and the radiological evidence of full evacuation of pus from the pleural cavity rather than to the decrease in the size of the empyema space. In our study, all patients whose general conditions had improved, their empyema space became obliterated gradually. Modified Elloeser flap technique may be the best way to treat 
an organized chronic empyema cavity despite the disadvantages which had been noticed therafter including the postoperative complaint of the patient, the long duration needed for closure of the open drainage window made in the chest wall, the daily need of dressing of the site of open drainage window postoperatively

\section{Results :}

Table 1 (Age distribution ): The youngest patient in this study was 20 years old and the oldest one was 60 years old. The highest incidence was among patients between (41-60) years old .

\begin{tabular}{|c|c|c|}
\hline Age of Patients & Number of Pateints & Percentage \\
\hline 1-20 years & 3 & $10 \%$ \\
\hline 21-40 years & 9 & $30 \%$ \\
\hline 41-60 yeas & 18 & $60 \%$ \\
\hline Total & 30 & $100 \%$ \\
\hline
\end{tabular}

and the long term need of antibiotics and analgesia after carrying out the surgical procedure. 


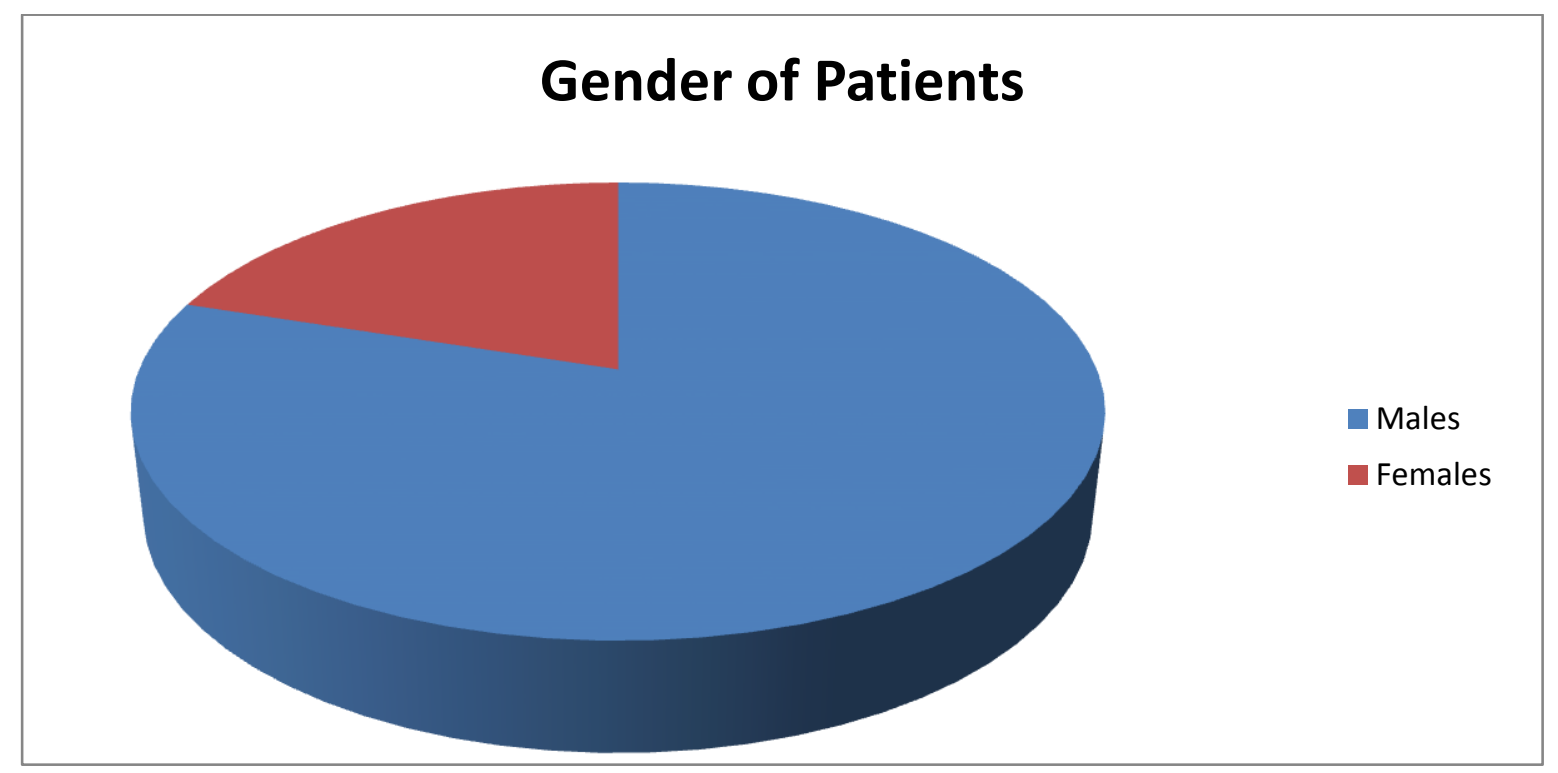

Figure 1 : (Sex of patients) : The incidence was higher among males ( $80 \%$ ) than femles $(20 \%)$

Table 2 ( Preoperative investigations ) : All patients underwent inventstigations (blood investigations, Chest x.ray, CT- scan ) before operation .

\begin{tabular}{|c|c|c|}
\hline \begin{tabular}{c|c|c|} 
Type of investigation the \\
patient undergo
\end{tabular} & $\begin{array}{c}\text { Number of patients } \\
\text { Chest x.ray }\end{array}$ & Percentage \\
\hline Chest Ct - scan & 30 & $100 \%$ \\
\hline Blood investigation & 30 & $100 \%$ \\
\hline
\end{tabular}

Table 3 (Types of surgical procedure ) : The commonest type of surgical procedure carried out was Elloeser flap whithout thoracoplasty and less common was Elloeser flap with thoracoplasty 


\begin{tabular}{|c|c|c|}
\hline \begin{tabular}{c|c|} 
Type of Surgical \\
Procedure
\end{tabular} & Number of Pateints & Percentage \\
\hline $\begin{array}{c}\text { Elloeser flap without } \\
\text { Thoracoplasty }\end{array}$ & 24 & $80 \%$ \\
\hline $\begin{array}{c}\text { Elloeser flap preceded by } \\
\text { Thoracoplasty }\end{array}$ & 6 & $20 \%$ \\
\hline Total & 30 & $100 \%$ \\
\hline
\end{tabular}

Table 4 ( Type of anaesthesia ) : The number of patients who underwent this operation under local anesthesia was large and constituting about $80 \%$ of the total number of patients while general anesthesia was offered to only $20 \%$ of the patients .

\begin{tabular}{|c|c|c|}
\hline Procedure & Number of patients & Percentage \\
\hline Local anesthesia & 24 & $80 \%$ \\
\hline General anaesthesia & 6 & $20 \%$ \\
\hline Total & 30 & $100 \%$ \\
\hline
\end{tabular}

Table 5 ( Site of Elloeser flap ) : The most common site of Elloeser flap was the posterior inferior location of thoracic cage which is the most dependant site for proper drainage of chronic empyema cavity.

\begin{tabular}{|c|c|c|}
\hline Site of Elloeser flap & Number of patients & Percentage \\
\cline { 2 - 2 } & 24 & $80 \%$ \\
\hline $\begin{array}{c}\text { Posterior inferior location of } \\
\text { thoracic cage }\end{array}$ & $\mathbf{2 4}$ & $\mathbf{2 0 \%}$ \\
\hline $\begin{array}{c}\text { Lateral inferior location of } \\
\text { thoracic cage }\end{array}$ & $\mathbf{3 0}$ & $\mathbf{1 0 0 \%}$ \\
\hline Total & & \\
\hline
\end{tabular}


Table 6 ( Comorbidities ) : Certain Co-morbidities could be recognized in patients with chronic empyema cavity like D.M., Hypertension, Ischemic heart disease \& Malignancy. Several patients had more than one Comrbidity.

\begin{tabular}{|c|c|c|}
\hline Co-Morbidities & Number of Patients & Percentage \\
\hline Malignancy & 5 & $20 \%$ \\
\hline D.M. & 12 & $40 \%$ \\
\hline COPD & 15 & $50 \%$ \\
\hline Hypertension & 3 & $10 \%$ \\
\hline Ischemic Heart Disease & 3 & $10 \%$ \\
\hline
\end{tabular}

Table 7 ( The indications of Elloeser flap ) : There are different indications of Elloeser flap in each patient and as following :

\begin{tabular}{|c|c|c|}
\hline Indication of Elloeser Flap & $\underline{\text { Number of Patients }}$ & $\underline{\text { Percentage }}$ \\
\hline $\begin{array}{l}\text { Recurrent malignant pleural } \\
\text { effusion complicated by chronic } \\
\text { empyema due to Bronchogenic } \\
\text { carcinoma }\end{array}$ & 3 & $10 \%$ \\
\hline $\begin{array}{c}\text { Recurrent malignant pleural } \\
\text { effusion complicated by chronic } \\
\text { empyema cavity due to } \\
\text { Rhabdomyosarcoma of chest } \\
\text { wall }\end{array}$ & 3 & $10 \%$ \\
\hline Unresolved \& infected & 6 & $20 \%$ \\
\hline
\end{tabular}




\begin{tabular}{|c|c|c|}
\hline $\begin{array}{c}\text { hemothorax due to Blunt } \\
\text { trauma ( Road traffic accident ) }\end{array}$ & & \\
\hline $\begin{array}{c}\text { Chronic empyema cavity due to } \\
\text { infected big hydatid cyst in the } \\
\text { liver (subphrenic source of } \\
\text { infection ) }\end{array}$ & 3 & $10 \%$ \\
\hline $\begin{array}{c}\text { Chronic tuberculous empyema } \\
\text { cavity + broncho pleural } \\
\text { effusion }\end{array}$ & 6 & $20 \%$ \\
\hline $\begin{array}{c}\text { Chronic pyogenic empyema } \\
\text { cavity }\end{array}$ & 6 & \\
\hline $\begin{array}{c}\text { Unresolved \& infected } \\
\text { hemothorax in a patient with } \\
\text { CVA due to fall from height }\end{array}$ & 3 & $20 \%$ \\
\hline Total & 30 & $10 \%$ \\
\hline
\end{tabular}

Table 8 ( Perioperative complications ) : The complications of Elloeser flap with or without Thoracoplasty included bleeding, pain \& permanent chest deformity. Several patients developed more than one complication.

\begin{tabular}{|c|c|c|}
\hline$\frac{\text { Complications during or }}{\underline{\text { after procedure }}}$ & $\underline{\text { Number of patients }}$ & $\underline{\text { Percentage }}$ \\
\hline Bleeding & 6 & $20 \%$ \\
\hline Pain & 30 & $100 \%$ \\
\hline $\begin{array}{l}\text { Gross Permanent chest } \\
\text { deformity }\end{array}$ & 9 & $30 \%$ \\
\hline
\end{tabular}




\begin{tabular}{|c|c|c|}
\hline $\begin{array}{c}\text { Minor Permanent chest } \\
\text { deformity }\end{array}$ & 21 & $70 \%$ \\
\hline Death & 6 & $20 \%$ \\
\hline
\end{tabular}

Table 9 (Duration of closure ) The duration after which the open drainage system closes varies widely between the patients depending on several factors including ( size of chronic empyema cavity, the presence of co-morbidities, adherence to antibiotics, the presence of bronchopleural fistula, etc...).

\begin{tabular}{|c|c|c|}
\hline$\frac{\text { Duration of Closure of }}{\underline{\text { Elloeser Flap }}}$ & Number of Patients & Percentage \\
\hline$(2-8)$ weeks & 9 & $30 \%$ \\
\hline (3-6) months & 7 & $20 \%$ \\
\hline ( $7-12)$ months & 1 & $20 \%$ \\
\hline More than one year & r & $10 \%$ \\
\hline Failure of Closure & 1 & $20 \%$ \\
\hline
\end{tabular}

\section{Discussion}

Eloesser flap technique was carried out in both sexes but the number of males was significantly higher $(80 \%)$ and any age group was suitable for this surgical procedure. Most of the patients were cachectic with profound loss of weight, fever, loss of appetite and one or more co-morbidity including D.M., hypertension, I.H.D., C.O.P.D. and malignancy. This is similar to the study made by Qais M. Ali ${ }^{(2)}$ which showed that the age of the patients ranged from 3 years to 70 years with a mean of 28 years with a sex incidence of 10 females $(19.23 \%)$ and 42 males $(80.77 \%)$ with one or more co-morbidity.

Chest $\mathrm{X}$ rays were showing total or semi-total collapse of the lung with airfluid level in the hemithorax involved by the empyema. Most of these patients were already on medical treatment according to their causative disease. This is also consistent with Qais M. Ali's study ${ }^{(2)}$. Our study highlights the usefulness of pleurocutaneous flap in three ways; the patient become free from the intercostal 
tube, become ambulatory and can undergo domiciliary treatment. It also helps in achieving re-expansion of the lung obviating any major definitive surgical procedure and finally it is suitable for sick patients who are not fit for general anaesthesia and major surgical operations such as thoracotomy. This is consistent with most studies done on chronic empyema cavity.

Open drainage is the oldest modality for the treatment of thoracic empyema. It was described 2400 years ago. In 1919 Sir William Osler required open drainage and rib resection for the treatment of empyema.

In 1935, Leo Eloesser, the surgeon who devised the procedure now associated

with his name, described the operation as constructing a window with a flap in chest wall as a one way valve, allowing egress of freely mobile fluid while preventing air from entering the pleural cavity and causing lung collapse. The original operation has been modified by substituting a comparatively wide open window thoracostomy by Wilcox ${ }^{(3)}$, Galvin $^{(4)}$ and others for the slit like one way valve opening described by Leo Eloesser. The valve like mechanism is not necessary in cases of chronic empyema cavity because the visceral and parietal pleura are fused at the margins of the empyema. This fusion isolates the empyema cavity from the rest of the pleural space, preventing lung collapse despite the presence of a large pleurocutaneous communication. The time at which the air filled pleural cavity is obliterated varies over a substantial range. According to our study, the chronic empyema cavity became obliterated within one year and is similar to the experience of Weissberg ${ }^{(5)}$ and Matthew P.Shapiro and collegues ${ }^{(6)}$ who recognized that closure of chronic empyema cavity varies widely between patients depending on several factors and the duration of closure may take several months and sometimes may extend up to one year. There was a good correlation between the size of chronic empyema cavity and the amount of time required for cavity closure. This is similar to the study made by Weissberg (5) but is different from the study made by Matthew P.Shapiro and collegues ${ }^{(6)}$ whose study did not show a good correlation between the size of the empyema cavity and the amount of time required for cavity closure. A tract persisted only in one case in our study after obliteration of chronic empyema cavity with no evidence of residual empyema on chest radiograph or CTscan.

Chest wall deformity persists after disappearance of empyema cavity due depression in the chest wall where the skin becomes in close proximity to the pleura \& lung, separated only by intervening granulation tissue. This goes with the study made by Weissberg ${ }^{(5)}$.

Eloesser flap was carried out mainly under local anaesthesia because most of the patients with chronic empyema cavity were sick and not fit for general anaesthesia and were too cachectic to tolerate thoracotomy for decortication or more aggressive treatment. In addition, the most dependant position was chosen for the Eloesser flap which is usually posteriorly and lower down of the thoracic cage in $80 \%$ of cases and this is consistent with the study made by Qais 
M. Ali (2), Weissberg (5), Matthew P.Shapiro and collegues ${ }^{(6)}$ and

Arvind Kohli and collegues ${ }^{(7)}$.

In our study, open drainage procedure was indicated for chronic empyema due to many causes like complicated chronic tuberculous effusion, unresolved traumatic haemothorax, complicated recurrent malignant pleural effusion and this goes with the study made by Qais $M$. Ali ${ }^{(2)}$. All patients had been exposed to tube thoracostomy previously and this also goes with the study made by Qais M. Ali ${ }^{(2)}$, Weissberg ${ }^{(5)}$, Matthew P.Shapiro and collegues ${ }^{(6)}$.

The mortality rate was $20 \%$ in our study and this was due to the original pathology (malignancy ) with empyema as an additional factor and not due to the surgical procedure ( Eloesser flap ) itself. This fact was also recognized in Qais $\mathrm{M}$. Ali's thesis ${ }^{(2)}$ in which the mortality rate was similar to ours $(17.41 \%)$ while the other perioperative complications which happened during and after the surgical procedure could be treated on conservative basis without need for another surgical operation and they include bleeding, pain and chest wall deformity. This is similar to other theses made on chronic empyema cavity like that made by Qais M. Ali ${ }^{(2)}$, Weissberg ${ }^{(5)}$, Matthew P.Shapiro and collegues ${ }^{(6)}$.

\section{Conclusion:}

1- The surgical procedure of Modified Eloesser flap was very effective in treatment of chronic empyema cavity in patients who did not respond to more conservative treatment like tube thoracostomy and/ or are not fit for major surgical interventions like thoracotomy and decortication.
2- $\quad$ An acceptable mortality rate was recognized in patients exposed to Modified Eloesser flap which was due to the underlying serious pathology in those patients like malignancy.

3- The perioperative complications of Modified Eloesser flap were treated on conservative basis.

\section{Recommendations:}

1- The posterior inferior site of thoracic cage is chosen for Modified Eloesser flap.

because it is the most dependant site for drainage of chronic empyema cavity.

2- $\quad$ Modified Eloesser flap is carried out usually under local anaesthesia because the patient is usually not fit for general anaesthesia.

3- Modified Eloesser flap may be accompanied by thoracoplasty if the empyema cavity is large.

4- Open drainage should not be ignored as one of the therapeutic options in treatment of advanced thoracic empyema.

5- Modified Eloesser might be the best therapeutic modality in cachectic patients where the facilities for more aggressive treatment are not possible.

\section{References}

1- $\quad$ Kaiser, Larry R.; Kron, Irving L.;

Spray, Thomas L., Mastery of 
Cardiothoracic Surgery, 2nd Edition, 2007.

2- Qais M. Ali, Department of Surgery, Al-Mustansiriya College of Medicine, Open Drainage with Rib Resection in The Treatment of Organized Thoracic Empyema, MMJ; 9(1):67-70, 2010.

3- Wilcox BR. Chronic empyema. In: Glenn's Thoracic and Cardiovascular Surgery; 4th ed. Philadelphia: W.B. Saunders \& Co.; 1983: pp 155.

4- $\quad$ Galvin IF, Gibbons JR, Maghout $\mathrm{MH}$. Bronchopleural fistula: a novel type of window thoracostomy. $J$ Thorac Cardiovasc Surg 1988; 96: 433-5.
5- Weissberg D, Empyema and bronchopleural fistula. Chest 1982;82:447-450.

6- Matthew P. Shapiro, M. Elon Gale and Benedict D. T. Daly. Department of Radiology, American Roenten Ray Society ( AJR ) 150;549552, March 1988.

7- $\quad$ Arvind Kohli, Gurjit Singh, Anita Vig, Kavi Raj Dubey and Rajinder Singh, Cardiothoracic and Vascular Surgery Unit, Pleurocutaneous Flap: How Useful It is in Management of Chronic Empyema Government Medical College, Jammu, India, 257-259, Vol.48, 2006.
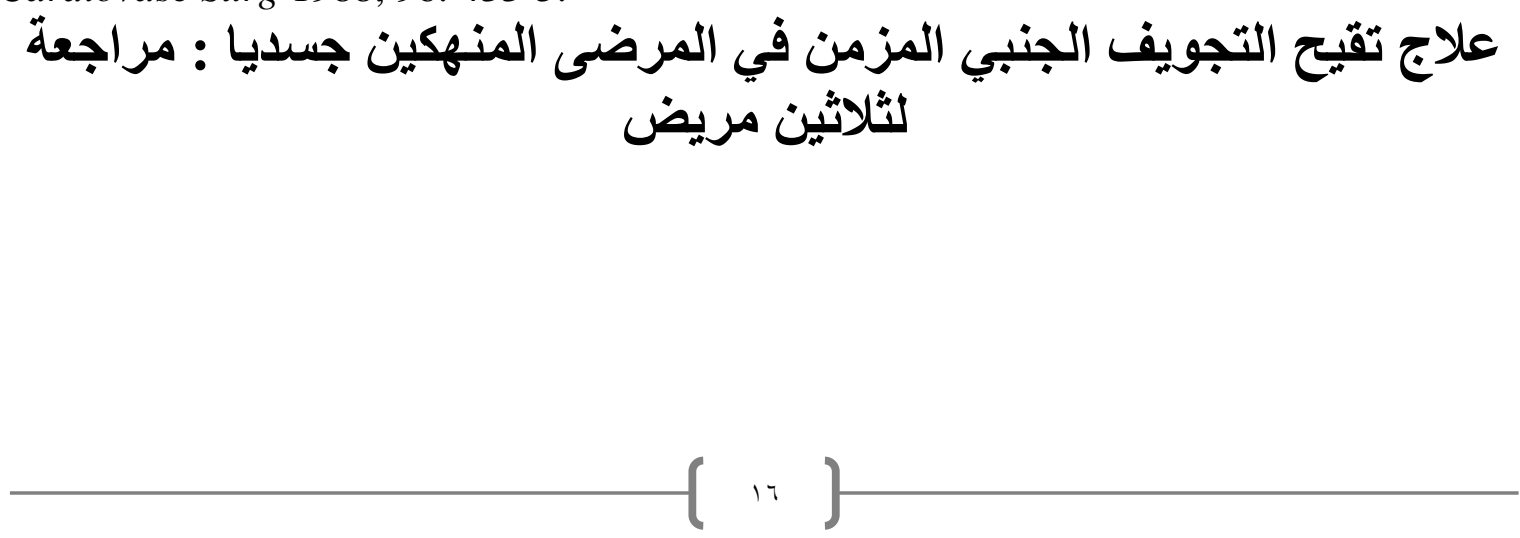
علي محسن عبيا

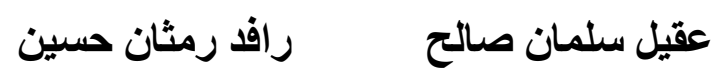

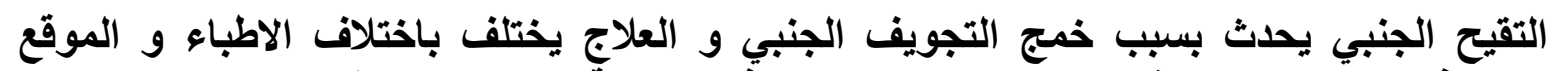

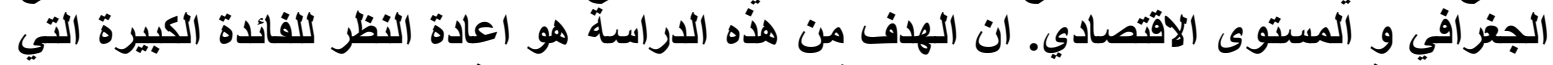

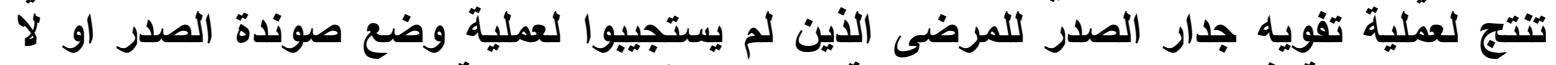

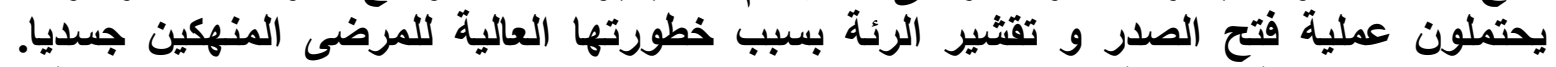

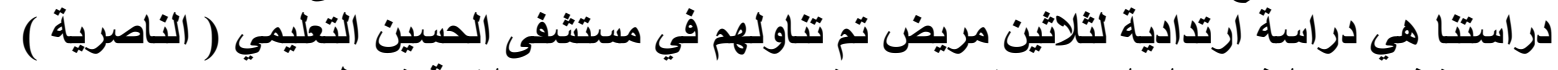

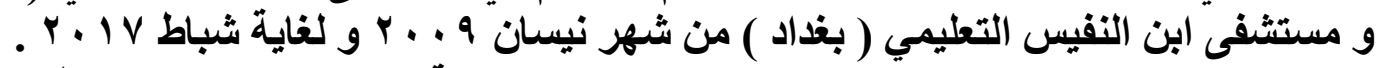

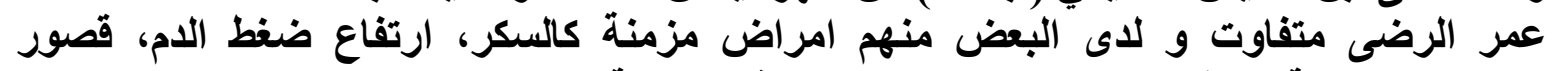

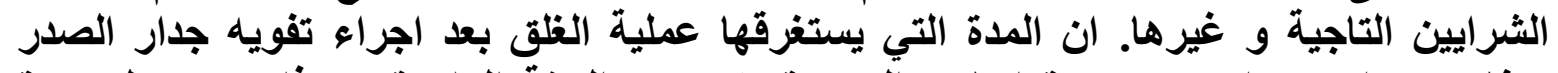

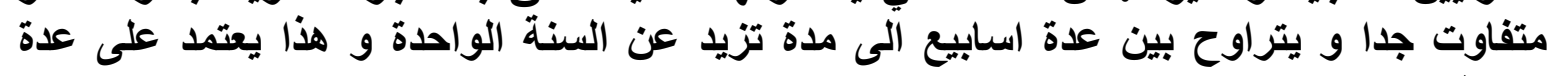

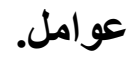

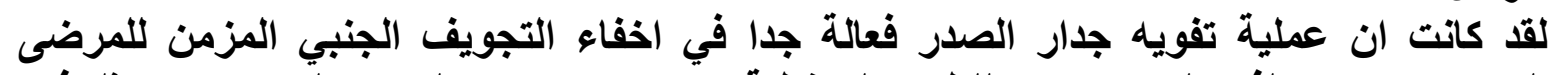

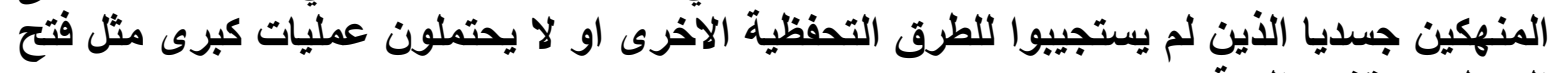
الصدلر و تقشير الرئة. 